\title{
Desempenho produtivo e respostas fisiopatológicas de tambaquis alimentados com ração suplementada com $\beta$-glucano
}

\author{
Edsandra Campos Chagas( ${ }^{(1)}$, Fabiana Pilarski(2), Róberson Sakabe ${ }^{(2)}$ e Flávio Ruas de Moraes ${ }^{(3)}$
}

\begin{abstract}
(1)EmbrapaAmazônia Ocidental, RodoviaAM-10, Km 29, Caixa Postal319, CEP69010-970 Manaus, AM. E-mail: edsandra.chagas@embrapa.br (2)Universidade Estadual Paulista (Unesp), Centro de Aquicultura, Laboratório de Patologia de Organismos Aquáticos, Via de Acesso Prof. Paulo Donato Castellane, s/no, CEP 14870-000 Jaboticabal, SP. E-mail: fabianap@caunesp.unesp.br, rsakabe@yahoo.com.br (3)Unesp, Departamento de Patologia Animal. E-mail: fruas@fcav.unesp.br
\end{abstract}

Resumo - O objetivo deste trabalho foi avaliar o efeito do imunoestimulante $\beta$-glucano na dieta do tambaqui (Colossoma macropomum) sobre o desempenho produtivo, as respostas fisiológicas e imunológicas, e a resistência ao desafio com Aeromonas hydrophila. O experimento foi conduzido em delineamento inteiramente casualizado, em arranjo fatorial $5 \times 2$, com cinco níveis de $\beta$-glucano na dieta $(0,0,1,0,2,0,4$ e $0,8 \%)$ e dois tempos de amostragem (antes e após o desafio com $A$. hydrophila), com três repetições. Os peixes $(28,65 \pm 0,49 \mathrm{~g}$; $12,14 \pm 0,07 \mathrm{~cm})$ foram alimentados, por 60 dias, com dieta $(28 \%$ de proteína bruta) suplementada com preparação comercial de $\beta$-glucano. Após o período de alimentação, avaliou-se o desempenho produtivo, e os peixes foram desafiados com A. hydrophila. Os parâmetros hematológicos e imunológicos (concentração e atividade de lisozima) foram avaliados antes e após o desafio bacteriano. Após o desafio bacteriano, observouse a ocorrência de anemia normocítica-normocrômica. A suplementação com $\beta$-glucano não alterou a concentração nem a atividade da lisozima; porém, a menor concentração de $\beta$-glucano $(0,1 \%)$ favoreceu maior sobrevivência para a espécie quando desafiada com Aeromonas hydrophila. A suplementação de $\beta$-glucano não exerce influência sobre o desempenho produtivo e nem sobre os parâmetros hematológicos do tambaqui.

Termos para indexação: Aeromonas hydrophila, Colossoma macropomum, imunoestimulantes.

\section{Productive performance and physiopathological responses of tambaqui fed with $\beta$-glucan enriched diet}

\begin{abstract}
The objective of this work was to evaluate the effect of the immunostimulant $\beta$-glucan in tambaqui (Colossoma macropomum) diet on the productive performance, physiological and immunological responses, and the resistance to Aeromonas hydrophila challenge. The experiment was carried out in a completely randomized design in a $5 \times 2$ factorial arrangement, with five levels of $\beta$-glucan in the diet $(0,0.1,0.2,0.4$, and $0.8 \%$ ) and two sampling times (before and after challenge with A. hydrophila), with three replicates. Fish $(28.65 \pm 0.49 \mathrm{~g} ; 12.14 \pm 0.07 \mathrm{~cm})$ were fed for 60 days with diets $(28 \%$ crude protein) supplemented with commercial $\beta$-glucan preparation. After the feeding period, the productive performance was evaluated, and fish were challenged with $A$. hydrophila. Hematological and immunological parameters (concentration and activity of lysozyme) were determined before and after the bacterial challenge. After bacterial challenge, the occurrence of normocytic-normochromic anemia was observed. $\beta$-glucan supplementation did not change lysozime concentration and activity; however, the lowest concentration of $\beta$-glucan $(0.1 \%)$ favored higher survival rates for the species when challenged with Aeromonas hydrophila. $\beta$-glucan supplementation does not influence tambaqui productive performance and hematological parameters.
\end{abstract}

Index terms: Aeromonas hydrophila, Colossoma macropomum, immunostimulants.

\section{Introdução}

No Brasil, a criação de espécies nativas vem crescendo nos últimos anos e, no caso do tambaqui (Colossoma macropomum) - a espécie mais criada no Norte do país -, tem se expandido nas regiões Nordeste, Centro-Oeste e Sudeste (Brasil, 2012).
O tambaqui apresenta excelente potencial para produção intensiva, principalmente pela fácil obtenção de juvenis, pelo bom potencial de crescimento (alcança $3 \mathrm{~kg}$ de peso após 12 meses em sistemas de viveiros/ barragens), pela alta produtividade, pela resistência a baixos níveis de oxigênio dissolvido e pela excelente utilização de alimentos (Melo et al., 2001; Araújo-Lima \& 
Gomes, 2005). Contudo, uma das principais dificuldades relacionadas à sua criação intensiva é a ocorrência de doenças parasitárias e bacterianas (Malta et al., 2001), como a causada pela bactéria Aeromonas hydrophila em peixes de água doce (Pilarski \& Sakabe, 2009).

Em razão da elevada ocorrência de doenças parasitárias e infecciosas, têm-se utilizado quimioterápicos e antimicrobianos na aquicultura. No entanto, o seu uso indiscriminado ocasiona problemas como o desenvolvimento de bactérias resistentes, a presença de resíduos de antibióticos nos tecidos de peixes comercializados e o impacto negativo no ambiente (Vivekanandhan et al., 2002; Taylor et al., 2011). Assim, o emprego de imunoestimulantes na prevenção de doenças em peixes vem sendo priorizado (Dalmo \& Bogwald, 2008).

Os imunoestimulantes são substâncias biológicas que podem incrementar as respostas específicas e não específicas de defesa dos animais (Chagas et al., 2009; Ganguly et al., 2010). Os efeitos benéficos dos imunoestimulantes consistem em aumentar a atividade de macrófagos, a fagocitose por neutrófilos e monócitos, e a produção de linfócitos, imunoglobulinas e lisozima, o que aumenta a resistência desses animais frente à infecção por organismos oportunistas (Gopalakannan $\&$ Arul, 2010). Entre estes compostos, destacam-se os glucanos.

Os glucanos são macromoléculas formadas por blocos de glicose unidos por meio de ligações $\beta(1-3)$ e $\beta(1-6)$, normalmente encontrados nas células de levedura e fungos. Nos peixes, o $\beta$-glucano pode favorecer a estimulação dos mecanismos de defesa não específicos, o que induz a atividade fagocitária dos macrófagos e aumenta sua capacidade de defesa contra patógenos, além de incrementar a produção de proteínas líticas, como a lisozima, e de proteínas do sistema complemento (Paulsen et al., 2001; Gopalakannan \& Arul, 2010).

Os efeitos benéficos do $\beta$-glucano são relatados em diferentes espécies de peixes (Dalmo \& Bogwald, 2008; Sealey et al., 2008; Gopalakannan \& Arul, 2010). Contudo, são escassas as pesquisas que avaliam o potencial desses suplementos à base de glucanos em peixes nativos brasileiros.

O objetivo deste trabalho foi avaliar o efeito do imunoestimulante $\beta$-glucano na dieta do tambaqui sobre o desempenho produtivo, as respostas fisiológicas e imunológicas, e a resistência frente ao desafio com A. hydrophila.

\section{Material e Métodos}

O experimento foi conduzido no Laboratório de Patologia de Organismos Aquáticos, no Centro de Aquicultura, da Universidade Estadual Paulista, Campus de Jaboticabal, SP, entre março e junho de 2009.

Utilizou-se o delineamento inteiramente casualizado, em arranjo fatorial $5 \times 2$, com cinco níveis de $\beta$-glucano na dieta $(0,0,1,0,2,0,4$ e $0,8 \%)$ e dois tempos de amostragem (antes e após o desafio com A. hydrophila), com três repetições.

Foram utilizados 225 juvenis de tambaqui (peso médio de $28,65 \pm 0,49 \mathrm{~g}$ e comprimento total de $12,14 \pm 0,07 \mathrm{~cm})$, que foram aclimatados em 15 tanques de $310 \mathrm{~L}$ durante 30 dias e receberam ração comercial para peixes onívoros, com $28 \%$ de proteína bruta. Após esse período, os peixes foram alimentados com a dieta suplementada com preparação comercial de $\beta$-glucano (Betamune, Biorigin, São Paulo, SP) nas concentrações de $0,0,1,0,2,0,4$ e $0,8 \%$. A alimentação foi fornecida duas vezes ao dia até a saciedade aparente, durante 60 dias. Nesse período, os parâmetros de qualidade de água, como temperatura $\left(29,25 \pm 0,06^{\circ} \mathrm{C}\right)$ e oxigênio dissolvido $\left(6,30 \pm 0,02 \mathrm{mg} \mathrm{L}^{-1}\right)$, foram monitorados três vezes por semana, por meio de monitor YSI 55 (YSI Incorporated, Yellow Springs, OH, EUA). Quinzenalmente, foram avaliados: alcalinidade (191,09 $\left.\pm 1,21 \mathrm{mg} \mathrm{L}^{-1}\right)$, por titulação, conforme American Public Health Association et al. (1998); pH $(8,18 \pm 0,01)$, com pHmetro Q400M2 (Quimis, Diadema, SP); e amônia total $\left(0,09 \pm 0,01 \mathrm{mg} \mathrm{L}^{-1}\right)$, pelo método de endofenol (American Public Health Association et al., 1998).

Ao final do período de alimentação, com os peixes previamente anestesiados (100 $\mathrm{mg} \mathrm{L}^{-1}$ de benzocaína), realizou-se a análise biométrica para obtenção dos parâmetros de crescimento em peso (g) e comprimento total $(\mathrm{cm})$, tendo-se calculado, a partir destes dados, o ganho de peso (peso final - peso inicial), a conversão alimentar aparente (alimento consumido/ganho de peso) e a sobrevivência (\%).

Após a avaliação do desempenho produtivo, foi realizado o desafio bacteriano com 21 peixes de cada tratamento com $\beta$-glucano (sete por repetição), os quais foram inoculados por meio de injeção intraperitoneal de $A$. hydrophila, na concentração de 1,0x10 $0^{8}$ UFC (protocolo no 013985/09), determinada em ensaios preliminares. Durante os 15 dias do 
ensaio, a cada 12 horas, foram registrados dados de mortalidade e a ocorrência de sinais clínicos de aeromonose.

A avaliação dos parâmetros hematológicos e imunológicos foi realizada antes e 15 dias após o desafio bacteriano com três peixes de cada repetição (nove peixes de cada tratamento). Para isso, com os peixes previamente anestesiados $\left(100 \mathrm{mg} \mathrm{L}^{-1} \mathrm{de}\right.$ benzocaína), procedeu-se à coleta sanguínea mediante a punção de vasos caudais com o auxílio de seringas sem anticoagulante, e o sangue foi separado em dois microtubos. Em um tubo, foi adicionada heparina para a determinação do hemograma, que incluiu a dosagem do percentual do hematócrito, pela técnica do microhematócrito (Goldenfarb et al., 1971); a dosagem da taxa de hemoglobina, pelo método da cianometahemoglobina (Collier, 1944); e a contagem de eritrócitos, por meio da diluição de 1:200 em solução de formol-citrato, tendo-se realizado a contagem em hemocitômetro. De posse desses dados, foram calculados os índices hematimétricos de Wintrobe (1934), compreendidos pelo volume corpuscular médio, pela hemoglobina corpuscular média e pela concentração de hemoglobina corpuscular média. No segundo tubo, não se adicionou anticoagulante para obtenção de soro, o qual ficou em temperatura ambiente por cerca de 2 horas para coagulação. O soro foi separado por centrifugação $(3.000 \mathrm{~g}, 5 \mathrm{~min})$, tendo sido armazenado a $-70^{\circ} \mathrm{C}$ para determinação da concentração e da atividade da lisozima por ensaio turbidimétrico, segundo Ellis (1990), com adaptações.

Os resultados obtidos foram expressos como média \pm erro-padrão da média. As diferenças obtidas entre as médias dos diferentes tratamentos foram estabelecidas por análise de variância, e as médias foram comparadas pelo teste de Tukey, a 5\% de probabilidade.

\section{Resultados e Discussão}

A suplementação da dieta do tambaqui com $\beta$-glucano $(0,0,1,0,2,0,4$ e $0,8 \%)$ por 60 dias não exerceu influência sobre os parâmetros de desempenho produtivo avaliados (peso e comprimento final, ganho de peso, conversão alimentar e sobrevivência). Apesar disso, o desempenho produtivo do tambaqui foi considerado satisfatório, em razão da escala experimental utilizada (Tabela 1). Resultados semelhantes foram obtidos para tilápia-do-nilo
(Oreochromis niloticus) e "sea bass" (Dicentrarchus labrax) alimentados com dietas suplementadas com $\beta$-glucano (Bagni et al., 2005; Whittington et al., 2005). Estes autores também não observaram aumento significativo no crescimento dos peixes após o período de administração do imunoestimulante.

Falcon (2007) avaliou a suplementação da dieta da tilápia-do-nilo com os mesmos níveis de $\beta$-glucano $(0,1$, $0,2,0,4$ e $0,8 \%$ ) e com vitamina C (400 e $600 \mathrm{mg} \mathrm{kg}^{-1}$ dieta), durante 60 dias, e constatou que a suplementação não teve influência no desempenho produtivo da espécie. Contudo, há estudos que descrevem o efeito benéfico do $\beta$-glucano sobre o desempenho produtivo dos peixes, principalmente quanto ao aumento da taxa de crescimento (Sealey et al., 2008; Dalmo \& Bogwald, 2008). Lin et al. (2011), ao avaliar a espécie Cyprinus carpio koi, que recebeu dieta suplementada com $\beta$-glucano, relataram maiores valores de peso final e taxa de crescimento específico, mas não observaram diferença na sobrevivência.

$\mathrm{O}$ bom desempenho produtivo obtido para o tambaqui, independentemente do nível de suplementação do $\beta$-glucano, refletiu-se na manutenção do equilíbrio orgânico dos peixes, como determinado pela avaliação dos parâmetros hematológicos em 60 dias de criação (Tabela 2). No presente trabalho, a suplementação de $\beta$-glucano na dieta do tambaqui não promoveu alterações no hematócrito, na hemoglobina, no número de eritrócitos, no volume corpuscular médio, na hemoglobina corpuscular média e na concentração de hemoglobina corpuscular média após 60 dias de criação, e os valores encontrados estão dentro da faixa considerada satisfatória para peixes hígidos (Tavares-Dias et al., 2009).

Após o desafio com a bactéria A. hydrophila, verificou-se redução significativa nos valores de hemoglobina $(0,0,2,0,4$ e $0,8 \%)$ e hemoglobina corpuscular média $(0,8 \%)$ (Tabela 2$)$.

A bactéria $A$. hydrophila é o agente etiológico da septicemia hemorrágica. Portanto, nos tambaquis inoculados com essa bactéria, observaram-se, após as 24 horas iniciais da inoculação, petéquias hemorrágicas, distensão da cavidade abdominal por ascite, lesões ulcerativas na superfície do corpo, hemorragia nas nadadeiras e órgãos internos, coloração enegrecida e peixes isolados do cardume.

Com relação às alterações sanguíneas causadas pelo desafio com $A$. hydrophila, observou-se a ocorrência de anemia nos tambaquis, classificada em 
normocítica-normocrômica (Lorenzi, 2006). De forma semelhante, houve redução nos valores de hematócrito após desafio bacteriano em pacu (Piaractus mesopotamicus) e tilápia-do-nilo alimentados com dietas suplementadas com $\beta$-glucano (Falcon, 2007; Biller, 2008). Esse quadro se deve à ocorrência de hemorragias provocadas por essa bactéria, que produz hemolisina, a causa mais comum de anemia hemolítica em peixes (Campbell \& Ellis, 2007).

Alterações sanguíneas, como o quadro de anemia observado em tambaquis, também foram relatados em outros estudos. Garcia \& Moraes (2009) desafiaram o pacu com a bactéria $A$. hydrophila e observaram, após 24 horas, a ocorrência de anemia normocítica-hipocrômica, além de redução dos níveis de proteínas totais e do número de trombócitos, leucócitos totais, linfócitos e eosinófilos, com aumento do número de neutrófilos e monócitos. De forma semelhante, em carpa comum (Cyprinus carpio) infectada com $A$. hydrophila, foi descrita diminuição de hematócrito, hemoglobina e número de eritrócitos, acompanhada de leucocitose (Harikrishnan et al., 2003).

Também há relatos de efeitos negativos de altas doses e prolongada alimentação com $\beta$-glucano sobre a resposta imune dos peixes e a resistência a doenças (Couso et al., 2003). No presente trabalho, as maiores concentrações de $\beta$-glucano ( 0,4 e $0,8 \%$ ) fornecidas na dieta do tambaqui por período prolongado (60 dias) também promoveram maior taxa de mortalidade após o desafio com A. hydrophila (Tabela 3), o que condiz com os estudos de Whittington et al. (2005), que mostraram que altas dosagens de $\beta$-glucano podem determinar a exaustão das células fagocíticas.

$\mathrm{O}$ fornecimento de dieta suplementada com $\beta$-glucano não alterou a taxa de mortalidade após o desafio bacteriano (Tabela 3). Em espécies nativas como o pacu, em que o nível de suplementação de $0,1 \%$ de $\beta$-glucano foi utilizado por sete dias, houve maior sobrevivência dos peixes quando desafiados com A. hydrophila (Biller, 2008). Kumari \& Sahoo (2006) também relataram aumento da resistência de

Tabela 1. Parâmetros de desempenho produtivo de tambaquis (Colossoma macropomum) alimentados, durante 60 dias, com dietas suplementadas com $\beta$-glucano. Os dados são apresentados com média \pm erro-padrão da média ${ }^{(1)}$.

\begin{tabular}{|c|c|c|c|c|c|}
\hline \multirow[t]{2}{*}{ Parâmetros } & \multicolumn{5}{|c|}{$\beta$-glucano (\%) } \\
\hline & 0,0 & 0,1 & 0,2 & 0,4 & 0,8 \\
\hline Peso final (g) & $78,78 \pm 2,85 \mathrm{a}$ & $80,24 \pm 2,83 a$ & $86,66 \pm 3,74 a$ & $82,90 \pm 3,27 a$ & $90,39 \pm 4,23 a$ \\
\hline Comprimento final $(\mathrm{cm})$ & $15,96 \pm 0,18 \mathrm{a}$ & $16,51 \pm 0,20 \mathrm{a}$ & $16,72 \pm 0,24 a$ & $16,45 \pm 0,25 \mathrm{a}$ & $16,14 \pm 0,28 \mathrm{a}$ \\
\hline Ganho de peso (g) & $52,17 \pm 2,66 \mathrm{a}$ & $51,7 \pm 4,74 a$ & $58,8 \pm 5,99 a$ & $52,62 \pm 8,43 a$ & $59,58 \pm 3,40 a$ \\
\hline Conversão alimentar & $2,13 \pm 0,15 a$ & $2,17 \pm 0,32 \mathrm{a}$ & $2,03 \pm 0,15 a$ & $2,19 \pm 0,41 \mathrm{a}$ & $1,9 \pm 0,06 \mathrm{a}$ \\
\hline Sobrevivência (\%) & $100,00 \pm 0,00 \mathrm{a}$ & $95,57 \pm 4,43 a$ & $100,00 \pm 0,00 \mathrm{a}$ & $93,33 \pm 6,67 \mathrm{a}$ & $100,00 \pm 0,00 \mathrm{a}$ \\
\hline
\end{tabular}

${ }^{(1)}$ Médias seguidas de letras iguais, nas linhas, não diferem entre pelo teste de Tukey, a 5\% de probabilidade.

Tabela 2. Parâmetros hematológicos de tambaquis (Colossoma macropomum) após suplementação de $\beta$-glucano na dieta antes e após desafio com Aeromonas hydrophila ${ }^{(1)}$.

\begin{tabular}{|c|c|c|c|c|c|c|}
\hline \multirow[t]{2}{*}{ Parâmetros ${ }^{(2)}$} & \multirow{2}{*}{$\begin{array}{c}\text { Tempo de } \\
\text { amostragem }\end{array}$} & \multicolumn{5}{|c|}{$\beta$-glucano (\%) } \\
\hline & & 0,0 & 0,1 & 0,2 & 0,4 & 0,8 \\
\hline Hematócrito & Antes & $28,13 \pm 1,53 \mathrm{aA}$ & $31,22 \pm 2,38 \mathrm{aA}$ & $29,00 \pm 4,09 \mathrm{aA}$ & $31,00 \pm 4,22 \mathrm{aA}$ & $33,71 \pm 3,92 \mathrm{aA}$ \\
\hline$(\%)$ & Após & $25,56 \pm 1,84 \mathrm{aA}$ & $23,33 \pm 2,52 \mathrm{aA}$ & $25,00 \pm 2,60 \mathrm{aA}$ & $25,22 \pm 1,95 \mathrm{aA}$ & $21,78 \pm 2,30 \mathrm{aA}$ \\
\hline Hemoglobina & Antes & $7,54 \pm 0,52 \mathrm{aA}$ & $7,51 \pm 0,67 \mathrm{aA}$ & $7,71 \pm 0,51 \mathrm{aA}$ & $7,86 \pm 0,41 \mathrm{aA}$ & $7,75 \pm 0,35 \mathrm{aA}$ \\
\hline$\left(\mathrm{g} \mathrm{dL}^{-1}\right)$ & Após & $5,09 \pm 0,56 \mathrm{aB}$ & $6,33 \pm 0,51 \mathrm{aA}$ & $5,29 \pm 0,67 \mathrm{aB}$ & $6,41 \pm 0,47 \mathrm{aB}$ & $5,19 \pm 0,50 \mathrm{aB}$ \\
\hline Número de eritrócitos & Antes & $2,16 \pm 0,21 \mathrm{aA}$ & $2,48 \pm 0,32 \mathrm{aA}$ & $2,17 \pm 0,25 \mathrm{aA}$ & $2,69 \pm 0,45 \mathrm{aA}$ & $2,49 \pm 0,27 \mathrm{aA}$ \\
\hline$\left(10^{6} \mathrm{~mm}^{-3}\right)$ & Após & $1,81 \pm 0,19 \mathrm{aA}$ & $1,84 \pm 0,22 \mathrm{aA}$ & $1,72 \pm 0,19 \mathrm{aA}$ & $2,14 \pm 0,26 \mathrm{aA}$ & $2,06 \pm 0,20 \mathrm{aA}$ \\
\hline VCM & Antes & $136,98 \pm 15,18 \mathrm{aA}$ & $151,62 \pm 18,97 \mathrm{aA}$ & $148,71 \pm 20,49 \mathrm{aA}$ & $141,36 \pm 25,39 \mathrm{aA}$ & $148,38 \pm 24,46 \mathrm{aA}$ \\
\hline$\left(\mu \mathrm{m}^{3}\right)$ & Após & $149,47 \pm 14,35 \mathrm{aA}$ & $143,37 \pm 23,46 \mathrm{aA}$ & $153,97 \pm 17,47 \mathrm{aA}$ & $136,38 \pm 20,90 \mathrm{aA}$ & $109,58 \pm 9,18 \mathrm{aA}$ \\
\hline HCM & Antes & $34,87 \pm 3,28 \mathrm{aA}$ & $33,71 \pm 2,56 \mathrm{aA}$ & $36,77 \pm 3,18 \mathrm{aA}$ & $33,72 \pm 7,18 \mathrm{aA}$ & $36,96 \pm 4,16 \mathrm{aA}$ \\
\hline$(\mathrm{pg})$ & Após & $31,19 \pm 5,44 \mathrm{aA}$ & $37,83 \pm 4,72 \mathrm{aA}$ & $31,61 \pm 3,13 \mathrm{aA}$ & $32,86 \pm 3,96 \mathrm{aA}$ & $26,23 \pm 2,59 \mathrm{aB}$ \\
\hline CHCM & Antes & $25,72 \pm 2,06 \mathrm{aA}$ & $24,68 \pm 3,93 \mathrm{aA}$ & $28,07 \pm 2,53 \mathrm{aA}$ & $24,81 \pm 3,90 \mathrm{aA}$ & $25,16 \pm 3,77 \mathrm{aA}$ \\
\hline$(\%)$ & Após & $21,85 \pm 3,85 \mathrm{aA}$ & $30,48 \pm 5,59 \mathrm{aA}$ & $22,32 \pm 2,71 \mathrm{aA}$ & $26,19 \pm 2,30 \mathrm{aA}$ & $25,34 \pm 3,09 \mathrm{aA}$ \\
\hline
\end{tabular}

${ }^{(1)}$ Médias seguidas de letras iguais, minúsculas nas linhas e maiúsculas nas colunas, não diferem pelo teste de Tukey, a $5 \%$ de probabilidade. ${ }^{(2)} \mathrm{VCM}$, volume corpuscular médio; HCM, hemoglobina corpuscular média; e CHCM, concentração de hemoglobina corpuscular média. 
juvenis de "Asian catfish" (Clarias batrachus), após o desafio com $A$. hydrophila, quando alimentados com dieta suplementada com $0,1 \%$ de $\beta$-glucano.

Alguns estudos conduzidos com $\beta$-glucano em espécies de peixes sugerem que a administração de dietas suplementadas com este imunoestimulante promove aumento da resistência contra infecções bacterianas e protozoárias (Kumari \& Sahoo, 2006; Lauridsen \& Buchmann, 2010). Este aumento na resistência a doenças nos peixes se dá, principalmente, pelo aumento dos mecanismos não específicos de defesa (Whittington et al., 2005), como por exemplo o aumento da atividade da lisozima (Paulsen et al., 2003).

A suplementação de $\beta$-glucano na dieta dos tambaquis por 60 dias promoveu aumento significativo na concentração e na atividade de lisozima dos peixes que receberam a suplementação de $0,2 \%$ de $\beta$-glucano, em comparação aos demais tratamentos, com exceção do tratamento de $0,1 \%$ de $\beta$-glucano (Tabela 4). Entretanto, todos os outros grupos apresentaram

Tabela 3. Mortalidade acumulada de tambaquis (Colossoma macropomum) alimentados com dietas suplementadas com $\beta$-glucano, por 60 dias, após desafio com Aeromonas hydrophila ${ }^{(1)}$.

\begin{tabular}{lc}
\hline$\beta$-glucano (\%) & Mortalidade (\%) \\
\hline 0,0 & $19,05 \mathrm{a}$ \\
0,1 & $9,52 \mathrm{a}$ \\
0,2 & $14,29 \mathrm{a}$ \\
0,4 & $38,10 \mathrm{a}$ \\
0,8 & $38,10 \mathrm{a}$ \\
\hline
\end{tabular}

${ }^{(1)}$ Médias seguidas de letras iguais, não diferem pelo teste de Tukey, a 5\% de probabilidade.

Tabela 4. Concentração e atividade de lisozima de juvenis de tambaquis (Colossoma macropomum) alimentados com dieta suplementada com $\beta$-glucano antes e após desafio com Aeromonas hydrophila ${ }^{(1)}$.

\begin{tabular}{llllll}
\hline \begin{tabular}{l}
$\beta$ \\
\multirow{2}{*}{-glucano }
\end{tabular} & \multicolumn{2}{c}{$\begin{array}{c}\text { Concentração de lisozima } \\
\left(\mu \mathrm{g} \mathrm{mL} \mathrm{m}^{-1}\right)\end{array}$} & & \multicolumn{2}{c}{$\begin{array}{c}\text { Atividade de lisozima } \\
\left(\mathrm{U} \mathrm{mL}^{-1}\right)\end{array}$} \\
\cline { 2 - 3 } \cline { 5 - 6 } & \multicolumn{1}{c}{ Antes } & Após & & Antes & Após \\
\hline 0,0 & $0,18 \pm 0,01 \mathrm{bA}$ & $0,24 \pm 0,04 \mathrm{aA}$ & & $30,64 \pm 1,56 \mathrm{bA}$ & $39,70 \pm 5,64 \mathrm{aA}$ \\
0,1 & $0,23 \pm 0,03 \mathrm{abA}$ & $0,23 \pm 0,02 \mathrm{aA}$ & & $39,14 \pm 5,20 \mathrm{abA}$ & $38,24 \pm 3,41 \mathrm{aA}$ \\
0,2 & $0,36 \pm 0,06 \mathrm{aA}$ & $0,22 \pm 0,01 \mathrm{aA}$ & & $58,98 \pm 9,77 \mathrm{aA}$ & $36,57 \pm 2,02 \mathrm{aA}$ \\
0,4 & $0,20 \pm 0,02 \mathrm{bA}$ & $0,26 \pm 0,03 \mathrm{aA}$ & & $34,59 \pm 2,49 \mathrm{bA}$ & $43,67 \pm 4,74 \mathrm{aA}$ \\
0,8 & $0,19 \pm 0,02 \mathrm{bA}$ & $0,22 \pm 0,02 \mathrm{aA}$ & & $32,70 \pm 3,34 \mathrm{bA}$ & $37,54 \pm 0,01 \mathrm{aA}$ \\
\hline
\end{tabular}

valores de concentração e atividade de lisozima dentro do mesmo intervalo de variação (Tabela 4). Após a realização do desafio bacteriano, observou-se que a concentração e a atividade de lisozima não foram afetadas pelos níveis de suplementação de $\beta$-glucano na dieta do tambaqui. Os valores da concentração e da atividade de lisozima em tambaquis são próximos aos observados em espécies nativas, como o pacu (Biller, 2008). Outros autores constataram que os níveis de lisozima em truta arco-íris, tilápia-do-nilo e carpa comum não aumentaram após a suplementação alimentar com $\beta$-glucano (Whittington et al., 2005; Selvaraj et al., 2006; Sealey et al., 2008).

No entanto, há divergência quanto aos resultados de estudos que avaliam o uso de $\beta$-glucano como imunoestimulante na criação de peixes. Essas divergências podem ser decorrentes dos diferentes métodos de administração, do nível e da duração da administração, da idade do peixe, além da variação intra e interespecífica (Dalmo \& Bogwald, 2008; Sealey et al., 2008). Assim, há a necessidade de maior conhecimento dos efeitos do $\beta$-glucano na modulação do sistema imune em peixes nativos, com a avaliação de novos protocolos de administração, por períodos mais curtos e por aplicação intermitente, para proteger os peixes em períodos que antecedam manejos mais intensos na criação.

\section{Conclusões}

1. A suplementação de $\beta$-glucano na dieta do tambaqui (Colossoma macropomum) por 60 dias não exerce influência sobre o desempenho produtivo e os parâmetros hematológicos.

2. A suplementação com $0,2 \%$ de $\beta$-glucano promove alterações moderadas em parâmetros imunológicos (concentração e atividade de lisozima).

3. O desafio com a bactéria Aeromonas hydrophila provoca quadro de anemia normocítica-normocrômica nos tambaquis, em todos os tratamentos com $\beta$-glucano.

\section{Agradecimentos}

À Empresa Brasileira de Pesquisa Agropecuária (Embrapa), ao Ministério da Pesca e Aquicultura (MPA) (Projeto Aquabrasil) e à Fundação de Amparo à Pesquisa do Estado de São Paulo (Fapesp), pelo apoio financeiro.

Pesq. agropec. bras., Brasília, v.48, n.8, p.899-905, ago. 2013 DOI: 10.1590/S0100-204X2013000800013 


\section{Referências}

AMERICAN PUBLIC HEALTH ASSOCIATION; AMERICAN WATER WORKS ASSOCIATION; WATER ENVIRONMENT FEDERATION. Standard methods for the examination of water and wastewater. New York: American Public Health Association, 1998. 1050p.

ARAÚJO-LIMA, C.A.R.M.; GOMES, L. de C. Tambaqui (Colossoma macropomum). In: BALDISSEROTTO, B.; GOMES, L. de C. (Ed.). Espécies nativas para piscicultura no Brasil. Santa Maria: Ed. UFSM, 2005. p.175-202.

BAGNI, M.; ROMANO, N.; FINOLA, M.G.; ABELLI, L.; SACAPIGLIATI, G.; TISCAR, P.G.; SARTI, M.; MARINO, G. Short- and long-term effects of a dietary yeast beta-glucan (Macrogard) and alginic acid (Ergosan) preparation on immune response in sea bass (Dicentrarchus labrax). Fish and Shellfish Immunology, v.18, p.311-325, 2005. DOI: J.FSI.2004.08.003.

BILLER, J.D. Respostas fisio-patológicas e desafio por Aeromonas hydrophila em pacu alimentado com ração suplementada com 1,3 $\boldsymbol{\beta}$-glucano. 2008. 114p. Dissertação (Mestrado) - Universidade Estadual Paulista, Jaboticabal.

BRASIL. Ministério da Pesca e AqüiculturA. Boletim estatístico da pesca e aquicultura: Brasil 2010. Brasília: MPA, 2012. 128p.

CAMPBELL, T.W.; ELLIS, C.K. Avian and exotic animal hematology and cytology. New York: Wiley-Blackwell, 2007. 287p.

CHAGAS, E.C.; PILARSKI, F.; SAKABE, R.; MASSAGO, H.; FABREGAT, T.E.H.P. Suplementos na dieta para manutenção da saúde de peixes. In: TAVARES-DIAS, M. (Ed.). Manejo e sanidade de peixes em cultivo. Macapá: Embrapa Amapá, 2009. p.132-225.

COLLIER, H.B. Standardization of blood haemoglobin determinations. Canadian Medical Association Journal, v.50, p.550-552, 1944.

COUSO, N.; CASTRO, R.; MAGARINOS, B.; OBACH, A.; LAMAS, J. Effects of oral administration of glucans on the resistance of gilthead seabream to pasteurellosis. Aquaculture, v.219, p.99-109, 2003. DOI: 10.1016/S0044-8486(03)00019-X.

DALMO, R.A.; BOGWALD, J. $\beta$-glucans as conductors of immune symphonies. Fish and Shellfish Immunology, v.25, p.384-396, 2008. DOI: j.fsi.2008.04.008.

ELLIS, A.E. Lysozyme assays. In: STOLEN, J.S.; FLETCHER, T.C.; ANDERSON, D.P.; ROBERTSON, B.S.; VAN MUISWINKEL, W.B. (Ed.). Techniques in fish immunology. [S.1.]: SOS publications, 1990. p.101-103. (Fish immunology technical communications, 1).

FALCON, D.R. Nível de suplementação de 1,3 $\boldsymbol{\beta}$-glucano e vitamina $\mathrm{C}$ em dietas para tilápia do Nilo: desempenho produtivo e parâmetros fisiopatológicos. 2007. 146p. Tese (Doutorado) Universidade Estadual Paulista, Jaboticabal.

GANGULY, S.; PAUL, I.; MUKHOPADHAYAY, S.K. Application and effectiveness of immunostimulants, probiotics, and prebiotics in aquaculture: a review. Israeli Journal of Aquaculture, v.62, p.130-138, 2010.
GARCIA, F.; MORAES, F.R. Hematologia e sinais clínicos de Piaractus mesopotamicus infectados experimentalmente com Aeromonas hydrophilA. Acta Scientiarum. Biological Sciences, v.31, p.17-21, 2009. DOI: 10.4025/actascibiolsci.v31i1.308.

GOLDENFARB, P.B.; BOWYER, F.P.; HALL, E.; BROSIOUS, E. Reproducibility in the hematology laboratory: the microhematocrit determination. American Journal of Clinical Pathology, v.56, p.35-39, 1971. DOI: 10.1111/j.1365-2109.2009.02368.x.

GOPALAKANNAN, A.; ARUL, V. Enhancement of the innate immune system and disease-resistant activity in Cyprinus carpio by oral administration of $\beta$-glucan and whole cell yeast. Aquaculture Research, v.41, p.884-892, 2010. DOI: 10.1111/j.1365-2109.200 9.02368.x.

HARIKRISHNAN, R.; NISHA RANI, M.; BALASUNDARAM, C. Hematological and biochemical parameters in common carp, Cyprinus carpio, following herbal treatment for Aeromonas hydrophila infection. Aquaculture, v.221, p.41-50, 2003. DOI: S0044-8486(03)00023-1.

KUMARI, J.; SAHOO, P.K. Dietary $\beta-1,3$ glucan potentiates innate immunity and disease resistance of Asian catfish, Clarias batrachus (L.). Journal of Fish Diseases, v.29, p.95-101, 2006. DOI: $10.1111 / j .1365-2761.2006 .00691 . x$.

LAURIDSEN, J.H.; BUCHMANN, K. Effects of short- and long-term glucan feeding of rainbow trout (Salmonidae) on the susceptibility to Ichthyophthirius multifiliis infections. Acta Ichthyologica et Piscatoria, v.40, p.61-66, 2010. DOI: 10.3750/ AIP2010.40.1.08.

LIN, S.; PAN, Y.; LUO, L.; LUO, L. Effects of dietary $\beta$-1,3-glucan, chitosan or raffinose on the growth, innate immunity and resistance of koi (Cyprinus carpio koi). Fish and Shellfish Immunology, v.31, p.788-794, 2011. DOI: j.fsi.2011.07.013.

LORENZI, T.F. Manual de hematologia: propedêutica e clínicA. Rio de Janeiro: Guanabara Koogan, 2006. 710p.

MALTA, J.C. de O.; GOMES, A.L.S.; ANDRADE, S.M.S. de; VARELLA, A.M.B. Infestações maciças por acantocéfalos, Neoechinorhynchus buttnerae Golvan, 1956, (Eoacanthocephala, Neoechinorhynchidae) em tambaquis jovens, Colossoma macropomum (Cuvier, 1818) cultivados na Amazônia Central. Acta Amazônica, v.31, p.133-143, 2001.

MELO, L.A.S.; IZEL, A.C.U.; RODRIGUES, F.M. Criação de tambaqui (Colossoma macropomum) em viveiros de argila/ barragens no Estado do Amazonas. Manaus: Embrapa Amazônia Ocidental, 2001.30p. (Embrapa Amazônia Ocidental. Documentos, 18).

PAULSEN, S.M.; ENGSTAD, R.E.; ROBERTSEN, B. Enhanced lysozyme production in Atlantic salmon (Salmo salar L.) macrophages treated with yeast $\beta$-glucan and bacterial lipopolysaccharide. Fish and Shellfish Immunology, v.11, p.23-37, 2001. DOI: 10.1006/fsim.2000.0291.

PAULSEN, S.M.; LUNDE, H.; ENGSTAD, R.E.; ROBERTSEN, B. In vivo effects of $\beta$-glucan and LPS on regulation of lysozyme activity and mRNA expression in Atlantic salmon (Salmo salar L.). Fish and Shellfish Immunology, v.14, p.39-54, 2003. DOI: 10.1006/fsim.2002.0416. 
PILARSKI, F.; SAKABE, R. Principais enfermidades diagnosticadas no Estado de São Paulo: profilaxia ou tratamento? In: SIMPÓSIO INTERNACIONAL DE NUTRIÇÃO E SAÚDE DE PEIXES, 3., 2009, Botucatu. Anais. Botucatu: Unesp, 2009. p.101-130.

SEALEY, W.M.; BARROWS, F.T.; HANG, A.; JOHANSEN, K.A.; OVERTURF, K.; LAPATRA, S.E.; HARDY, R.W. Evaluation of the ability of barley genotypes containing different amounts of $\beta$-glucan to alter growth and disease resistance of rainbow trout Oncorhynchus mykiss. Animal Feed Science and Technology, v.141, p.115-128, 2008. DOI: j.anifeedsci.2007.05.022.

SELVARAJ, V.; SAMPATH, K.; SEKAR, V. Adjuvant and immune stimulatory effects of $\beta$-glucan administration in combination with lipopolysaccharide enhances survival and some immune parameters in carp challenged with Aeromonas hydrophilA. Veterinary Immunology and Immunopathology, v.114, p.15-24, 2006. DOI: j.vetimm.2006.06.011.

TAVARES-DIAS, M.; ISHIKAWA, M.M.; MARTINS, M.L.; SATAKE, F.; HISANO, H.; PÁDUA, S.B. de; JERÔNIMO, G.T.; SÁ, A.R.S. de. Hematologia: ferramenta para o monitoramento do estado de saúde de peixes em cultivo. In: SARAN NETO, A.; MARIANO, W. dos S.; SÓRIA, S.F.P. (Ed.). Tópicos especiais em saúde e criação animal. São Carlos: Pedro \& João Editores, 2009. p.43-80.

TAYLOR, N.G.H.; VERNER-JEFFREYS, D.W.; BAKER-AUSTIN, C. Aquatic systems: maintaining, mixing and mobilising antimicrobial resistance? Trends in Ecology and Evolution, v.26, p.278-284, 2011. DOI: j.tree.2011.03.004.

VIVEKANANDHAN, G.; SAVITHAMANIA, K.; HATHAB, A.A.M.; LAKSHMANAPERUMALSAMY,P.Antibiotic resistance of Aeromonas hydrophila isolated from marketed fish and prawn of South India. International Journal of Food Microbiology, v.76, p.165-168, 2002. DOI: S0168-1605(02)00009-0.

WHITTINGTON, R.; LIM, C.; KLESIUS, P.H. Effect of dietary $\beta$-glucan levels on the growth response and efficacy of Streptococcus iniae vaccine in Nile tilapia, Oreochromis niloticus. Aquaculture, v.248, p.217-225, 2005. DOI: j.aquaculture.2005.04.013.

WINTROBE, M.M. Variations in the size and hemoglobin content of erythrocytes in the blood of various vertebrates. Folia Haematologica, v.51, p.32-49, 1934.

$\overline{\text { Recebido em } 26 \text { de agosto de } 2011 \text { e aprovado em } 24 \text { de junho de } 2013}$ 